\title{
POPULATION ATTRIBUTABLE FRACTION AND PREDICTORS OF TYPE 2 DIABETES MELLITUS INCIDENCE IN ADULT POPULATION IN BOGOR, WEST JAVA
}

\author{
Woro Riyadina1), Ekowati Rahajeng1), Iwan Ariawan², \\ Pradana Soewondo3) \\ 1)National Institute of Health Research and Development, \\ Ministry of Health Republic Indonesia \\ 2)Faculty of Public Health, Universitas Indonesia \\ 3)Endocrine Department, Faculty of Medicine, Universitas Indonesia
}

\begin{abstract}
Background: In Indonesia, the incidence rate of type 2 Diabetes Mellitus (T2DM) was higher than other non-communicable diseases. As such the disease needs the best intervention. This study aimed to estimate Population Attributable Fraction (PAF) and predictors in adults.

Subjects and Method: This retrospective cohort study was conducted from 2012 until 2018 in five Districts, Bogor City, West Java. An adult population of 4,074 subjects aged $\geq 25$ years was selected. The dependent variable was T2DM incidence. The independent variables included hypertension, obesity, and triglyceride levels. The dependent and independent variables were measured by physical examination and laboratory tests. The data were analyzed using Hazard Ratio and Cox proportional hazard model.

Results: PAF of obesity was $34.27 \%$, so it was able to reduce 607 T2DM cases. PAF of obesity and hypertension was $47.12 \%$, so it was able to reduce 835 T2DM cases. PAF of obesity, hypertension, and triglyceride levels altogether was 56.1\%, so it was able to reduce 995 T2DM cases. Predictors of T2DM included hypertension ( $\mathrm{HR}=1.54 ; 95 \% \mathrm{CI}=1.27$ to $1.86 ; \mathrm{p}=0.001)$, obesity $(\mathrm{HR}=2.00 ; 95 \% \mathrm{CI}=1.62$ to $2.48 ; \mathrm{p}<0.001)$, and triglyceride levels $(\mathrm{HR}=1.86 ; 95 \% \mathrm{CI}=1.53$ to 2.26; $\mathrm{p}=0.001$ ).

Conclusion: Obesity, hypertension, and triglyceride levels are predictors of T2DM in adults. Primary prevention of T2DM incidence should be targeted to reducing obesity, hypertension, and triglyceride levels.
\end{abstract}

Keywords: population attributable fraction, predictors, T2DM, adults.

\section{Correspondence:}

Woro Riyadina. National Institute of Health Research and Development, Ministry of Health, Indonesia. Jl. Percetakan Negara 29, Central Jakarta. Email: w.riyadina02@gmail.com. Mobile: 081297673074 . 